\title{
Pigmentocracia: classe, raça e gênero no sistema de bem-estar social sul-africano
} Pigmentocracy: class, race, and gender in the South African
welfare system

\author{
Evandro Alves Barbosa Filho* \\ Ana Cristina de Souza Vieira** \\ Solange Rocha***
}

\begin{abstract}
Resumo - O artigo analisa como as relações sociais de classe, raça e gênero presentes na formação social da África do Sul resultaram na constituição de um sistema de bem-estar social pigmentocrático. O estudo é qualitativo e se fundamenta na teoria da consubstancialidade das relações sociais de classe, raça e gênero produzida pela sociologia crítica sul-africana. Para o levantamento dos corpora foram realizadas revisão de literatura e análise de documentos oficiais. Foram analisados documentos produzidos desde o fim do período colonial até o ano de 1996. O estudo identificou que as relações de segregação engendraram um amplo sistema de bem-estar social orientado à ascensão e proteção social das famílias brancas. Enquanto isso, negros, mestiços e asiáticos se tornaram cada vez mais destituídos de direitos. Mesmo com o fim do apartheid, o sistema de bem-estar social sul-africano continua (re)produzindo a pigmentocracia, a partir das condicionalidades neoliberais que orientaram a transição à democracia.

Palavras-chave: África do Sul; bem-estar social; classe; raça e gênero; consubstancialidade das relações sociais.

Abstract - This paper analyzes how the social relations of class, race, and gender present in the social formation of South Africa resulted in the constitution of a pigmentocratic system of social welfare. The study is qualitative and it's based on the theory of the consubstantiality of class, race, and gender social relations produced by South African critical sociology. For the survey of corpora, literature review and analysis of official documents were carried out. Documents from the last years of the colonial
\end{abstract}

\footnotetext{
* Doutor em Serviço Social pela Universidade Federal de Pernambuco (UFPE). Pós-doutorando, Bolsista PNPD - CAPES/FACEPE na UFPE, Brasil. E-mail: evealves85@yahoo.com.br. ORCID: 0000-0002-2944-3388.

** Doutora em Serviço Social pela Pontifícia Universidade Católica de São Paulo (PUC-SP), Professora titular da Universidade Federal de Pernambuco (UFPE), Brasil. E-mail: anacvieira12@gmail.com. ORCID: 0000-00028844-5375.

*** Doutora em Serviço Social pela Universidade Federal de Pernambuco - UFPE. Pesquisadora associada do Departamento de Sociologia da University of Cape Town - UCT, África do Sul. E-mail: msolgrocha@gmail.com. ORCID: 0000-0002-7442-6878.
} 
\} PIGMENTOCRACIA: CLASSE, RAÇA E GÊNERO - BARBOSA FILHO, E. A.; VIEIRA, A. C. S.; ROCHA, S. \}

DOI: $10.12957 /$ REP.2019.45247

period up to the year 1996 were analyzed. The study identified that the segregation relations generated a comprehensive system of social welfare oriented towards the social empowerment and social protection of white families. Meanwhile, Blacks, Coloureds, and Asians have become increasingly deprived of rights. Even with the end of apartheid, the South African welfare system continues (re)producing pigmentocracy. It stems from the neoliberal conditions that led the transition to democracy.

Keywords: South Africa; social welfare; social class; race; gender; consubstantiality of social relations.

\section{Introdução}

Desde o início da colonização holandesa, em 1652, a África do Sul é atravessada por relações de segregação política, econômica e social baseadas nas ideologias de supremacia racial branca. Neste país, a racialização da ultraexploração da força de trabalho negra e não branca, assim como sua estruturação via sistema colonial e de Estado, são elementos centrais à criação de um sistema de bem-estar social que reflete e reproduz a estratificação por classe, sexo e raça do país, estruturando um sistema oficial de capitalismo racial.

O capitalismo racial é uma das singularidades das relações capitalistas na África do Sul, resultando do intenso imbricamento entre exploração de classe e raça que tomou forma no país por vias oficiais, implicando relações de sexagem racializadas e estruturas institucionais materializadas pelo Estado capitalista. Estas visavam preservar os trabalhadores brancos do pauperismo decorrente da lei geral de acumulação de capital. Portanto, resulta do pacto entre elites e classes trabalhadora de origem europeia e se sustenta na ultraexploração da força de trabalho negra (FEINSTEIN, 2005; TERREBLANCHE, 2005; DAVIE; 2015).

Este capitalismo racial baseia-se em ideologias religiosas protestantes, no racismo científico e no nacionalismo africâner, como também no seu discurso sobre a necessidade de ascensão social das famílias brancas pobres. Dessa forma, instituiu um sistema de segregação total, resultando na destituição dos direitos políticos, civis e sociais dos sul-africanos negros, concomitantemente à subalternização crescente das populações coloured (mestiça) e asiática e à formação de um Estado de bem-estar social amplo e universal apenas para os brancos, que nunca foram mais do que $20 \%$ da população do país (DAVIE, 2015; TERREBLANCHE, 2005). Diante do exposto, o objetivo deste artigo é analisar como as relações de classe, raça e gênero se expressam na constituição do sistema de bem-estar social pigmentocrático da África do Sul.

O estudo é qualitativo e se fundamenta na teoria da consubstancialidade das relações sociais produzida pela sociologia crítica sulafricana, a partir de autores como Sampie Terreblanche (2005), Grace Davie (2015) e Charles Feinstein (2005). Para estes intelectuais, o desenvolvimento 


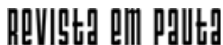

\} PIGMENTOCRACIA: ClASSE, RAÇA E GÊNERO - BARBOSA FILHO, E. A.; VIEIRA, A. C. S.; ROCHA, S. \}

DOI: $10.12957 /$ REP.2019.45247

das relações capitalistas na África do Sul não pode ser criticamente analisado sem atribuir centralidade ao imbricamento entre classe social, raça e relações sociais de sexo.

Classe social é entendida como o lugar que homens e mulheres ocupam nas relações de produção e nas forças produtivas. Considera-se que as classes sociais, sobretudo a que vive da venda da força de trabalho, além de não serem homogêneas, são codeterminadas pelas relações sociais de raça, que a partir da formação social do país e das ideologias que fundamentaram os seus diversos sistemas políticos protegem os brancos das desigualdades sociais e das formas mais severas de dominação e subalternidade, especialmente os homens brancos, a partir da ideia de supremacia racial. Assim, as relações de classe, raça e gênero são elevadas à condição de relações sociais estruturantes e estruturadoras do real, sendo imbricadas e forças motrizes da história de mulheres e homens.

Para o levantamento dos corpora, foram realizadas revisão de literatura e análise de documentos oficiais coletados durante pesquisa de campo realizada no país africano. Foram analisados os documentos produzidos pelo e/ou para o Estado sul-africano desde o início da Revolução Mineral, ocorrida em 1867, até 1996, ano em que o Governo do partido que pôs fim a mais de 350 anos de regimes de segregação racial, o African National Congress ${ }^{1}$ (ANC), publicou a primeira Constituição Nacional pósApartheid.

O corpus documental foi submetido à análise crítica de discurso. Dessa análise, que buscava identificar as implicações das relações sociais de classe, raça e gênero na constituição do sistema de bem-estar social no país e da revisão de literatura, foram elaborados os tópicos de desenvolvimento deste trabalho, como a organização pigmentocrática do bem-estar social por meio do Estado. Vale ressaltar que a pesquisa que deu origem a este artigo foi financiada pela Coordenação de Aperfeiçoamento de Pessoal de Nível Superior (Capes).

\section{A questão das famílias brancas pobres e a implantação do Apartheid (1867-1948)}

Os primeiros invasores europeus a chegarem no sul do Continente Africano foram os holandeses, ainda no século XVII. A eles seguiram-se protestantes franceses e alemães no decorrer do século XVIII. Estes fluxos migratórios de colonos brancos que desejavam construir um país europeu na África criaram a comunidade bôer ou afrikaner (FEINSTEIN, 2005). Profundamente isolados do desenvolvimento histórico europeu e em uma terra de solos pouco férteis, os bôeres desenvolveram uma pecuária rudimentar e

\footnotetext{
${ }^{1}$ Congresso Nacional Africano.
} 


\section{ReVIStG PMI PDUtD}

\} PIGMENTOCRACIA: CLASSE, RAÇA E GÊNERO - BARBOSA FILHO, E. A.; VIEIRA, A. C. S.; ROCHA, S. \}

DOI: $10.12957 /$ REP.2019.45247

descobriram no grande número de povos autóctones a principal "matériaprima" que a África Ihes oferecia: a força de trabalho de mais 1,5 milhões de africanos. Esta foi intensamente explorada no trabalho doméstico, na pecuária e na agricultura.

Como consequência, dentro de pouco tempo os africanos negros eram a única parcela da população que trabalhava. Essa total dependência do trabalho escravo e servil, e o completo desprezo por qualquer forma de produtividade e pelo trabalho manual, transformaram o europeu no bôer e deram ao seu conceito de raça um significado primordialmente econômico (ARENDT, 2012; TERREBLANCHE, 2005).

Porém, os bôeres não foram os únicos a lutar pelo domínio da África do Sul. Os britânicos enfrentaram e venceram os africâneres pelo controle das províncias do Cabo e de Natal. Mas foi apenas com a descoberta de diamantes em Kimberley, em 1867, e a descoberta de ouro na área em volta de onde atualmente se localiza Joanesburgo, em 1886, que começa a história moderna da África do Sul, a chamada Revolução Mineral. A atividade mineradora aprofundou as relações capitalistas no campo e nas cidades e proletarizou grande parte da população de todos os grupos raciais (FEINSTEIN, 2005).

Segundo Grace Davie (2015) e Charles Feinstein (2005), as jazidas de diamantes de Kimberley e as minas de ouro de Witwatersrand ocasionaram a chegada de grandes levas de exploradores. A maioria vinha da Inglaterra, mas havia bálticos, alemães, holandeses etc. Esses colonos eram os "homens supérfluos" do industrialismo europeu e expressavam mais aptidão à especulação do que à indústria organizada. Esses indivíduos não se integravam nas estruturas de organização política da classe trabalhadora vigentes na Europa; eles queriam ser senhores, burgueses. Logo, só os homens negros e mestiços trabalhavam nas minas, na agricultura e nas funções mais subalternas (FEINSTEIN, 2005; TERREBLANCHE, 2005).

Desde meados do século XIX, a união entre bôeres e demais colonos europeus legitimou a criação das primeiras estruturas e serviços de proteção social às famílias pobres, condicionadas pela raça, ou melhor, pela branquitude (DAVIE, 2015). A legislação e os serviços sociais se voltavam para proteção social às famílias brancas das consequências da exploração capitalista sobre a crescente massa de trabalhadores brancos urbanos. Nesse sentido, em 1913, o Ato Nacional de Proteção à Criança (Children's Protection Act) subsidiou bolsas de auxílio financeiro para crianças brancas de famílias pobres. A partir de 1926, o Ministério da Educação contava com recursos para pensões para mães, madrastas e avós que cuidassem de crianças brancas.

Além de responder às necessidades sociais imediatas das frações mais pauperizadas da classe trabalhadora branca, o embrionário sistema de bem-estar social sul-africano começou a se preocupar com as possibilidades de degeneração moral e miscigenação decorrentes da proletarização e da 


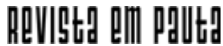

\} PIGMENTOCRACIA: CLASSE, RAÇA E GÊNERO - BARBOSA FILHO, E. A.; VIEIRA, A. C. S.; ROCHA, S. \}

DOI: $10.12957 /$ REP.2019.45247

interação das famílias brancas pobres com outras etnias. Outro temor das classes dominantes era de que, integrados aos negros, mestiços e indianos na venda da força de trabalho e no cotidiano urbano, os trabalhadores brancos desenvolvessem solidariedade e consciência de classe inter-raciais (DAVIE, 2015; KLAUSEN, 2004). A preocupação com a pobreza entre brancos se aprofundou no contexto da crise capitalista de 1929, que ocasionou a perda de emprego de muitos trabalhadores de origem europeia, progressivamente substituídos por negros, mão de obra de 10 a 12 vezes mais barata, resultando no crescimento da pobreza entre as famílias brancas, especialmente da comunidade africânder (FEINSTEIN, 2005).

A crescente problematização entre políticos, intelectuais e reformadores sociais conservadores em torno do problema das pessoas brancas pobres, o poor white people problem, resultou na realização do estudo que demarcaria o futuro das fronteiras raciais do bem-estar social na África do Sul a: A Comissão Carnegie de Estudos Sobre o Problema da Pobreza entre Brancos (Carnegie Commission of Inquiry into the Poor White Problem) (CARNEGIE COMISSION, 1932). Esta comissão de pesquisa, fundada pela Carnegie Corporation de Nova York (EUA) realizou estudos em todas as regiões do país entre os anos de 1929 e 1932. Tinha por objetivo investigar as causas e possíveis soluções para o problema do empobrecimento da população branca. O grupo desenvolveu duas teorias sobre a questão.

A primeira, fundamentada nas ideias eugenistas do racismo científico, defendia que as famílias brancas pobres representavam em si a causa do problema, sendo necessário promover o rígido controle de natalidade e impedir que estes indivíduos biologicamente "fracos" contaminassem os bons exemplares da população de origem europeia. Como resposta, esta tese incentivava a imigração de europeus considerados puros como solução à decadência quantitativa e qualitativa dos brancos no país.

A segunda teoria afirmava que o problema tinha sua origem no desenvolvimento capitalista liberal, que ocasionava urbanização, proletarização e desrespeito às clivagens raciais e morais, igualando brancos e pessoas de cor a partir dos seus lugares nas relações capitalistas de produção. Para esta teoria, a questão seria resolvida por meio de políticas sociais e econômicas que protegessem integralmente as famílias brancas da precarização e da degeneração moral, decorrentes da exposição às outras raças e ao liberalismo britânico. Esta acabou sendo a teoria aceita pelo Estado, pelos grupos políticos, acadêmicos e pelos reformadores sociais, já que frações da elite africânder e as lideranças da Igreja Reformada Holandesa se opunham às medidas de controle de natalidade sobre as famílias brancas pobres, dos quais mais de 70\% eram bôeres (DAVIE, 2015; KLAUSEN, 2004).

Nesse contexto, Estado, Igreja Reformada Holandesa, instituições filantrópicas e governos locais foram chamados pelas classes dominantes a criar ações assistenciais direcionadas às famílias brancas pobres e, pela primeira vez, essas medidas de aliviamento da pobreza e de controle sobre os 


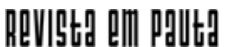

\} PIGMENTOCRACIA: ClASSE, RAÇA E GÊNERO - BARBOSA FILHO, E. A.; VIEIRA, A. C. S.; ROCHA, S. \}

DOI: $10.12957 /$ REP.2019.45247

trabalhadores brancos foram financiadas pelo Governo Nacional. Ao mesmo tempo que aumentavam os seus investimentos em serviços sociais para os brancos, os governos nacionais e locais vinham diminuindo os já incipientes investimentos sociais para as populações coloured, asiática e negra. O discurso político era de que os direitos de cidadania deveriam ser privilégios apenas dos sul-africanos civilizados, ou seja, os brancos.

Em 1934, Leila Reitz, assistente social e primeira mulher a fazer parte do Parlamento Sul-Africano, alertou os membros do Parlamento sobre a grave situação de empobrecimento das famílias brancas, afirmando que esta constituiria "um risco para a vida moral do país, um risco para eles mesmos, um risco para a manutenção da ordem social e, acima de tudo, um risco à própria civilização branca" (PATEL, 2013, p.95). Reitz ainda afirmava que a África do Sul deveria se preocupar mais do que qualquer outra nação com o bem-estar social dos seus cidadãos (brancos), pois ela tinha que enfrentar o "problema da cor", a expressiva maioria negra e a presença de mestiços e asiáticos (SOUTH AFRICA, 1934). A preservação do sistema de bem-estar social baseado na branquitude era tão extensa que, no final da década de 1930, ao debaterem sobre definir um "salário digno" para homens brancos, funcionários do Departamento de Bem-Estar Social e membros do Parlamento estabeleceram que mesmo uma família branca de classe operária sustentada por um único salário masculino deveria dispor de recursos para ter uma empregada doméstica, obviamente uma mulher negra (SEEKINGS; MOORE, 2013).

Mas a implementação desse sistema de privilégios à população branca por meio das políticas do Estado encontrava limites nas ideias liberais defendidas pelas frações da burguesia de origem britânica que, mesmo sendo minoria, era a principal proprietária da indústria mineradora e ocupava as principais posições no Estado. Diante disso, a reação da classe trabalhadora e de setores da elite política africânder não demorou.

No início dos anos 1940, enfatizando as injustiças patrocinadas pelos britânicos e pelo capital estrangeiro, e exagerando os "perigos" da inundação negra (black swanping), os ideólogos africâneres fomentaram racismo inverso e paranoia entre os brancos pobres, quando reafirmavam a ameaça de outros grupos presentes no país. A ameaça "vinda de cima": os britânicos e seu capitalismo liberal; e a ameaça "vinda de baixo": a maioria negra e a sua suposta ameaça à cultura, à "pureza racial" e à nação africânder (TERREBLANCHE, 2005).

Para se organizar enquanto sujeito coletivo, a classe trabalhadora africânder, que sempre foi a maior e mais pobre comunidade branca do país, criou associações e partidos políticos na defesa da causa afrikaner contra a emancipação política da população negra, que só passou a ter direito ao voto em 1994, e contra o poder político e econômico da comunidade britânica. Dessa forma, articulou-se em torno do Partido Nacional, ou National Party, cujas ideologias orientariam o Estado sul- 


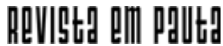

\} PIGMENTOCRACIA: ClASSE, RAÇA E GÊNERO - BARBOSA FILHO, E. A.; VIEIRA, A. C. S.; ROCHA, S. \}

DOI: $10.12957 /$ REP.2019.45247

africano e todas as esferas da vida social, desde a esfera pública até a sexualidade.

Os significativos efeitos da crise de 1929 e os resultados da Comissão Carnegie sobre a classe trabalhadora, bem como a elite política africânder, fizeram o racismo e o nacionalismo se radicalizarem. Então, nas eleições gerais de 1948, o Partido Nacional se desfez da coalizão com o Partido Trabalhista, Labour Party, iniciada em 1924, e se lançou como o partido da causa africânder e de fortalecimento da proteção aos trabalhadores e às famílias brancas contra o liberalismo, o comunismo, a integração racial e a livre concorrência com os negros no mercado de trabalho. Tais propostas, obviamente, tiveram grande aceitação entre a classe trabalhadora branca, garantindo a vitória do Partido Nacional.

Essa considerável transformação no cenário político sul-africano teve implicações severas para a população negra. A política de indução à ascensão social das famílias brancas demandou maiores níveis de exploração sobre as pessoas de cor, não só no espaço público. Dessa forma, a oferta de bem-estar social ao homem branco e à sua família passava pela disposição da força de trabalho negra também no ambiente doméstico. Sendo assim, enquanto a ampla maioria dos homens negros só tinha como sobreviver vendendo sua força de trabalho na mineração, na agricultura e na indústria, as trabalhadoras negras tinham como principal destino o trabalho doméstico. Estas deveriam servir docilmente às mulheres brancas e aos seus patrões, devendo chamar-Ihes, respectivamente, de madame e mestre.

As trabalhadoras domésticas negras eram destituídas até dos seus nomes de origem, considerados complicados demais para serem pronunciados, e obrigadas a morar nas dependências da casa dos seus patrões (DAVIE, 2015). Estas mulheres eram significadas pelo regime do Apartheid como parte fundamental do sistema de bem-estar social garantido pelo Estado racista às famílias brancas. Grande parte das trabalhadoras negras tiveram que deixar seus filhos confinados nas homelands sob os cuidados de avós, tias ou de membros femininos da família extensa. Livrar as mulheres brancas casadas de grande parte do trabalho doméstico e das funções de cuidado visava materializar outro objetivo do Partido Nacional: incentivá-las a gerar e educar rigorosamente o maior número possível de filhos, garantindo a expansão do volk (povo) sul-africano.

\section{Da instituição do Apartheid à luta pela desracialização do Estado}

Com a chegada do Partido Nacional ao poder em 1948, por meio da eleição de Daniel François Malan (1948-1954) sob o slogan "Apartheid" - palavra que significa desenvolvimento em separado -, pela primeira vez um partido predominantemente africânder assumiu o Governo Nacional. Sem experiência e relativamente pobre, esta fração da população branca 


\section{ReVIStG PMI PDUtD}

\} PIGMENTOCRACIA: CLASSE, RAÇA E GÊNERO - BARBOSA FILHO, E. A.; VIEIRA, A. C. S.; ROCHA, S. \}

DOI: $10.12957 /$ REP.2019.45247

passou a controlar grande parte da riqueza nacional, sobretudo as empresas estatais e as estruturas governamentais, utilizando o poder político e a mão de obra negra, abundante e barata, para promover a industrialização e sustentar um amplo sistema de bem-estar social. Este foi rigidamente organizado a partir das categorizações raciais e financiado, compulsoriamente, pelos trabalhadores negros (DAVIE, 2015; TERREBLANCHE, 2005).

A agenda do Partido Nacional buscava aprofundar e tornar mais rigorosa a ordem racial e socioeconômica iniciada com a Revolução Mineral. Além de tornar mais severa a destituição política e econômica dos não brancos, a proposta do Apartheid era adaptar a moderna produção capitalista às necessidades sociais da minoria branca, livrando-os das implicações sociais da lei geral de acumulação de capital.

Desde então, as famílias brancas receberam extensa assistência em termos de desmercantilização da educação, da saúde pública, dos programas de bem-estar e de assistência social, bem como de ações afirmativas no mercado de trabalho, que garantiam pleno emprego e altos salários. Esse conjunto de ações do Estado de bem-estar social racista do Apartheid objetivava a ascensão social dos brancos pobres o mais rápido possível. O desprezo destes pelo trabalho manual, considerando trabalho de negros (kaffir work), aumentou a participação dos sul-africanos nativos nas piores e insalubres funções. Aos coloured e asiáticos foram delegadas as funções intermediárias (FEINSTEIN, 2005). No tocante ao bem-estar social, parcos recursos foram alocados para a maioria africana negra que, na época, equivalia a cerca de $61 \%$ da população, e muitas políticas do Apartheid, nas décadas de 1950 e 1960, foram concebidas para subalternizar ainda mais as populações não brancas (TERREBLANCHE, 2005).

A segregação racial se tornou mais rígida e violenta a partir da instituição do Ato Nacional de Registro Populacional (The Population Registration Act) núm. 30, de 1950. Esta lei nacional sobre o registro e a classificação racial demandava que as pessoas nascidas no país fossem identificadas e registradas desde o nascimento dentro de um dos quatro diferentes grupos raciais reconhecidos pelo Estado racista: brancos, coloured, asiáticos e bantu (ou sul-africanos negros). Este sistema de classificação e segregação oficial era um dos pilares do Apartheid.

A implementação dessa lei entre crianças, jovens e adultos era caracterizada pela realização de testes humilhantes, como por meio da verificação de traços físicos e linguísticos. Tipo do cabelo, cor da pele e formato do nariz foram utilizados para estabelecer a branquitude idealizada pelo regime, marginalizando homens e mulheres que não atendiam a estes padrões raciais e separando definitivamente pessoas de uma mesma família, quando recebiam classificações raciais diferentes. A partir de então, foi-se intensificado o controle sobre quem poderia e onde poderia viver no território sul-africano, marginalizando cada vez mais os coloureds e asiáticos e enviando grande parte da população negra para as homelands e os mestiços 


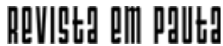

\} PIGMENTOCRACIA: ClASSE, RAÇA E GÊNERO - BARBOSA FILHO, E. A.; VIEIRA, A. C. S.; ROCHA, S. \}

DOI: $10.12957 /$ REP.2019.45247

para conjuntos habitacionais situados nas regiões periféricas fora das cidades, as chamadas planícies (flats).

As homelands ou bantustões eram as dez unidades político-territoriais criadas pelo regime do Apartheid, em 1951, que correspondiam às áreas mais pobres do país e a apenas $13 \%$ do território nacional. Eram as porções do território criadas como reservas de retribalização artificial e compulsória para diminuir a presença dos negros no país. Essas áreas se tornaram as reservas de mão de obra, de onde eram retirados os trabalhadores migrantes, majoritariamente homens, destituindo as famílias negras de figuras paternas. O campesinato dos bantustões foi empobrecido por excesso de culturas no solo, de pastagem de gado em áreas inadequadas e restritas de terra, e pela escassez crônica de mão de obra masculina. $\mathrm{O}$ investimento em serviços sociais e de saúde era muito incipiente, ofertado por filantropos ou privatizados.

Nas cidades, os negros que conseguiam manter-se (porque tinham trabalhado num emprego permanente por, no mínimo, dez anos) e os demais grupos raciais eram obrigados a viver em áreas separadas dos brancos, e uns dos outros. Todos os serviços e espaços públicos eram segregados: escolas, universidades, hospitais, transporte público, praias, cinemas, bancos de parque, banheiros, bibliotecas, filas etc. Grande parte dessa estrutura de segregação só teve fim em 1994. Outra significativa implicação da retribalização forçada das homelands é o fato de que os negros perderam a cidadania sul-africana, tornaram-se estrangeiros em seu próprio país e precisavam portar um passaporte interno, chamado dompas. A permissão para circular no país era determinada pela condição de trabalhador assalariado imigrante.

Esta estrutura oficial de segregação racial e territorial orientada a proteger as famílias brancas do processo de pauperização e da suposta degeneração moral decorrente da integração racial foi idealizada e modernizada pelo Professor de Serviço Social e Psicologia Hendrik Verwoerd, então docente da University of Stellenbosch. A legitimidade de Verwoerd como defensor dos interesses dos sul-africanos brancos era tão grande que ele foi eleito Primeiro Ministro em 1958.

O projeto pigmentocrático de bem-estar social do Apartheid foi tão bem-sucedido à ascensão social da minoria branca que, a partir da década de 1970, estes dispunham de alta renda, demandando cada vez menos os serviços prestados pelo Estado. Os esquemas de seguros e serviços contributivos privados, com parca regulação estatal, experimentaram uma grande adesão e foram amplamente subsidiados pelo regime do Apartheid. Nesse período de intensa migração dos brancos para as estruturas privadas de bem-estar, os imperativos do crescimento econômico e da estabilidade política levaram o Estado social pigmentocrático a uma relocação lenta e incipiente de recursos para coloureds e asiáticos e, posteriormente, aos negros, especialmente entre os que viviam em áreas urbanas, nas favelas (PATEL, 2013). 


\section{ReVIStG PMI PDUtD}

\} PIGMENTOCRACIA: CLASSE, RAÇA E GÊNERO - BARBOSA FILHO, E. A.; VIEIRA, A. C. S.; ROCHA, S. \}

DOI: $10.12957 /$ REP.2019.45247

Esse crescente investimento em serviços de bem-estar social para os coloureds e asiáticos, que acompanhou o fim da década de 1970 e os anos 1980, foi ocasionado pela tentativa do Partido Nacional de conseguir adesão destes grupos às suas políticas, já que a classe trabalhadora negra tinha se organizado enquanto classe para si, promovendo greves em escala nacional, luta armada e exigindo que o sistema de bem-estar social fosse estendido para os sul-africanos de todas as raças (DAVIE, 2015).

Reprimidos pelo Estado e com pouca capacidade de integração via mercado, profundamente regulado pelas fronteiras raciais do Apartheid, os sul-africanos de cor dependiam majoritariamente dos laços familiares e de parentesco para a provisão de cuidados e apoio financeiro. Essa dependência da família extensa e dos grupos primários para compensar os limitados recursos salariais e o incipiente acesso aos serviços sociais se aprofundou no contexto da crise capitalista de 1973, que ocasionou a queda do preço dos commodities minerais, aumentando os níveis de pauperização entre as famílias não brancas. Logo, os negros, os coloureds e asiáticos perceberam que as reformas sociais minimalistas promovidas pelo Partido Nacional não iriam resultar na superação da sua exploração, e que esta só viria com o fim do Apartheid (TERREBLANCHE, 2012).

O African National Congress ${ }^{2}$ (ANC) foi o movimento social e, posteriormente, o partido político que sintetizou e articulou grande parte das lutas de negros sul-africanos em torno da causa do fim do Apartheid e da estrutura econômica que o sustentava, propondo a socialização da riqueza nacional e a universalização do bem-estar social, como constava desde 1955 no seu principal manifesto, a Freedom Charter $^{3}$ (AFRICAN NATIONAL CONGRESS, 1955). No contexto do aprofundamento da crise política e econômica do país que se iniciou na segunda metade dos anos 1980, o ANC e o Partido Nacional, diante das pressões internacionais, se viram obrigados a iniciar o diálogo sobre os termos da transição à democracia. Se ainda não estava claro quem iria governar o país, era evidente a essas duas forças que o sistema de bem-estar social deveria abranger todos os sul-africanos. Esta inesperada concessão por parte do Partido Nacional era uma tentativa de restringir a transição do Apartheid para o sistema político democrático à desracialização dos serviços sociais do Estado, mantendo intacta a propriedade privada dos meios de produção e paralisando a agenda de reformas de base.

No processo de transição à democracia, o ANC fez várias concessões às classes dominantes. Representantes do Banco Mundial, do Fundo

\footnotetext{
${ }^{2}$ O ANC foi criado, enquanto movimento social, em 1912, sendo o mais antigo movimento de libertação nacional do Continente Africano. Tornou-se partido político oficialmente registrado apenas em 1994, para concorrer na eleição presidencial realizada naquele ano (TERREBLANCHE, 2005).

${ }^{3}$ A Carta da Liberdade, ou Freedom Charter, era o mais importante manifesto político do ANC. Apresentava o Projeto de Estado e de bem-estar social almejado pelo movimento, em que todos os sul-africanos, independente da raça e da classe social, teriam amplos direitos sociais, civis e políticos, garantidos por um Estado provedor.
} 
Monetário Internacional e think tanks neoliberais conduziram os debates e projeções sobre qual deveria ser o papel do Estado e do mercado na África do Sul pós-Apartheid (DAVIE, 2015; TERREBLANCHE, 2012). Mesmo pondo fim ao regime de segregação racial, o novo Governo de maioria negra liderado por Nelson Mandela, que venceu as primeiras eleições gerais de 1994, implementou os acordos construídos entre elite política do ANC e importantes frações do capital nacional e internacional, determinando o modelo de sistema de bem-estar social no pós-Apartheid.

\section{Bem-estar social pós-Apartheid: neoliberalismo, focalização e centralidade na família}

A partir de 1994, a democracia pós-Apartheid desracializou os serviços de bem-estar social, ampliando, portanto, a cobertura para todos os sul-africanos, sem discriminação racial. Mas os pactos políticos realizados pelo ANC com os órgãos multilaterais comprometiam os investimentos em políticas sociais, restringindo o investimento estatal em políticas sociais e promovendo o aumento da responsabilização das famílias na provisão de bem-estar social. Obviamente, as famílias brancas estavam bem mais preparadas financeiramente que as dos outros grupos étnicos para assumir tais responsabilidades.

Neste cenário em que as expectativas de emancipação política por meio de um Estado Social ampliado não estavam sendo respondidas, foi publicada a Constituição Nacional de 1996, considerada uma das mais avançadas do mundo. Foi a primeira do país a reconhecer a igualdade entre homens e mulheres, a abolição da segregação racial em todas esferas da vida social e o casamento entre pessoas do mesmo sexo. Além disso, se comprometeu, por meio da seção 27 , com a criação de políticas sociais que responderiam aos direitos sociais e humanos de todos os cidadãos.

Porém, a nova Constituição também afirmava que a implementação desse sistema de bem-estar social seria progressiva e condicionada pela existência de recursos, o que seria decidido pelo Governo Nacional. Este se comprometeu com o ideário e as diretrizes neoliberais, compromisso que resultou em uma das mais ortodoxas contrarreformas já implementadas em todo o mundo, o Growth, Employment and Redistribution ${ }^{4}$ (SOUTH AFRICA, 1996).

Desde então, o papel do Estado na oferta de bem-estar social foi reduzido a uma série de programas de transferência de renda mínima e à fragmentada oferta de serviços básicos, focalizados nos segmentos mais subalternizados: as famílias negras que vivem em situação de extrema pobreza. Se comparado aos serviços ofertados durante o Apartheid, o sistema

${ }^{4}$ Crescimento, emprego e redistribuição. 


\section{ReVIStG PMI PDUtD}

\} PIGMENTOCRACIA: ClASSE, RAÇA E GÊNERO - BARBOSA FILHO, E. A.; VIEIRA, A. C. S.; ROCHA, S. \}

DOI: $10.12957 /$ REP.2019.45247

de bem-estar retrocedeu em vários aspectos, como na oferta de cuidados médicos e de assistência social, especialmente entre os idosos, deficientes e desempregados, sendo estes últimos, $31,5 \%$ da população economicamente ativa (PATEL, 2013).

Diante do subfinanciamento e do consequente colapso dos serviços sociais públicos decorrente da implementação do Gear, mesmo os sul-africanos pobres vêm recorrendo cada vez mais ao mercado para a provisão de serviços sociais. O sucateamento dos serviços públicos também resultou em uma maior carga de trabalho doméstico executado pelas muIheres, segundo a divisão sexual do trabalho, e uma pressão financeira adicional, principalmente para as famílias negras e coloureds, sobretudo aquelas chefiadas por mulheres (DAVIE, 2015).

$\mathrm{Na}$ atualidade, o Estado Social sul-africano expressa um complexo sistema misto de bem-estar, que combina o crescente papel do mercado a um Estado social seletivo e focalizado nas famílias em pobreza extrema, além da crescente responsabilização dos arranjos familiares na provisão de renda e de cuidados. Vale ressaltar que os arranjos familiares sul-africanos vêm passando por profundas transformações em sua composição e na dinâmica relacional entre os seus integrantes.

Nesse sentido, além de serem tradicionalmente responsáveis pelo trabalho doméstico e de cuidados, as mulheres negras e mestiças cada vez mais vêm assumindo a condição de provedoras, por meio dos salários ou das pensões pagas aos idosos pobres, as old age grants (PATEL, 2013). Elas estão, majoritariamente, inseridas em trabalho doméstico, no setor de cuidados e nas áreas que recebem os mais baixos salários. As negras, não raramente, são simultaneamente financeiramente responsáveis pelo cuidado sobre as crianças, jovens e demais adultos, mas mesmo assim são subalternizadas pelos seus maridos ou filhos homens, mesmo quando estes são materialmente dependentes delas (SEEKINGS; MOORE, 2013).

Um volume significativo de assistência financeira é ofertado desde 1994 por meio dos programas de transferência de renda. No governo de Nelson Mandela (1994-1999), as bolsas de transferência de renda, social grants, foram ofertadas a 4 milhões de cidadãos pertencentes às famílias mais pobres. Em 2017, o número de beneficiários chegou a 16,9 milhões, representando $30 \%$ da população total do país, de 56.308 .533 habitantes, dos quais 15 milhões eram child grants, bolsas destinadas às famílias em pobreza extrema que tinham crianças e adolescentes em idade escolar.

A extensão do acesso a serviços sociais básicos, mas não universalizados, não resultou em uma melhora significativa na qualidade de vida de muitas pessoas vulneráveis que vivem nas áreas mais precárias, especialmente as rurais. Em 2015, 17\% de todos os sul-africanos, aproximadamente 12 milhões de pessoas, não recebiam nenhum rendimento salarial, social grants ou subvenções sociais. Essa expressiva parcela da população, composta por adultos sem trabalho formal ou informal, crianças ou idosos sem 


\section{ReVIIStg am Poutt}

\} PIGMENTOCRACIA: ClASSE, RAÇA E GÊNERO - BARBOSA FILHO, E. A.; VIEIRA, A. C. S.; ROCHA, S. \}

DOI: $10.12957 /$ REP.2019.45247

benefícios sociais, representa uma expressiva lacuna no regime residual de bem-estar social do país.

\section{Considerações finais}

Como forma de responder às crescentes demandas da classe trabalhadora branca e dos nacionalistas africânderes, que desde a Revolução Mineral sofriam os efeitos da pauperização, decorrente do aprofundamento das relações capitalistas no país, a África do Sul criou uma série de serviços de combate à pobreza voltados exclusivamente às famílias brancas pobres. Porém, nem mesmo esta rede de serviços sociais foi suficiente para mitigar o empobrecimento das frações proletárias de origem europeia, especialmente da africânder, decorrente da crise capitalista de 1929.

Publicado ainda sob os efeitos da primeira grande crise do século $\mathrm{XX}$, o relatório da Comissão Carnegie evidenciou o aprofundamento do pauperismo entre as famílias brancas, elevando o problema dos brancos pobres à condição de prioridade para o sistema de bem-estar social (CARNEGIE COMISSION, 1932). O aprofundamento desse sistema de bem-estar foi obstaculizado pelo liberalismo da elite britânica, contrária ao alto nível de intervenção do Estado na economia e na produção de bem-estar social, como era desejado pelos africânderes. Esse contexto foi propício para a radicalização do racismo e do nacionalismo afrikaner, que nas eleições nacionais de 1948 levaram o Partido Nacional à vitória, resultando na implantação do Apartheid.

Durante os 46 anos que permaneceu no poder, o Partido Nacional instituiu um sistema de bem-estar social que refletia e refratava a pigmentocracia do país, ofertando um sistema universal aos brancos, um residual aos coloureds e asiáticos e a indigência e a filantropia aos negros. Além da existência de três modelos distintos de bem-estar social no mesmo país, a África do Sul tem outra particularidade histórica que, assim como o racismo e o conflito de classe, atravessam os distintos regimes políticos que tomaram forma no país nos últimos 366 anos: a importância da força de trabalho negra para a produção de bem-estar de grupos brancos, totalmente realizada por mulheres, a partir das relações estruturais e estruturantes de classe, raça e gênero, que as posicionam como a população mais subalternizada do país austral.

As mulheres negras proviam trabalho doméstico e de cuidados para a totalidade das famílias brancas, e sua disponibilidade era parte do projeto racista de bem-estar social. Elas também eram provedoras de seus familiares, confinados nas homelands e sob os cuidados de outras mulheres da família extensa. O seu emprego pelas famílias brancas revela outra expressão das desigualdades de gênero dentro do sistema racista: elas garantiam que as mulheres brancas casadas tivessem como prioridade máxima a ma- 


\section{ReVIStG PMI PDUtD}

\} PIGMENTOCRACIA: ClASSE, RAÇA E GÊNERO - BARBOSA FILHO, E. A.; VIEIRA, A. C. S.; ROCHA, S. \}

DOI: $10.12957 /$ REP.2019.45247

ternidade. Sendo assim, mesmo pertencentes à raça e à classe dominante, as brancas eram subalternizadas pelo machismo dominante nas ideologias supremacistas e machistas do Partido Nacional.

Se a desmercantilização das necessidades sociais e a cobertura da proteção social aos brancos sul-africanos atingiram níveis semelhantes ao dos welfare states escandinavos, em nenhum outro país, mesmo dentre os de capitalismo central, a mão de obra doméstica e os care services foram tão importantes para ampliar o bem-estar social das famílias. As mulheres negras, as coloureds e asiáticas sofreram uma tripla opressão, a partir das relações sociais de raça, classe e gênero, que as posicionava como subalternas ao racismo do sistema oficial no espaço público e às hierarquias de gênero e raça na esfera privada.

O fim do Apartheid e a Constituição de 1996 não parecem apontar para uma reversão na situação das mulheres de cor sul-africanas. O maior investimento social dos governos pós-Apartheid em social grants e as condicionalidades destes continuam atreladas à pobreza extrema, concentrada entre os negros, e à execução de atividades atribuídas às mulheres. Estes programas de transferência de renda pouco alteraram as relações de classe, gênero e raça no país. Passados 23 anos do fim do Apartheid, as mulheres negras ainda desempenham a maior parte do trabalho de socialização das crianças e dos jovens, de cuidados em caso de adoecimento e de assistência aos idosos. Além disso, são a maioria nos trabalhos domésticos e mais precários, realizando desgastantes jornadas de trabalho para os seus patrões e familiares.

Portanto, as concepções e modelos de bem-estar social precisam ser revistos criticamente, a partir do olhar da consubstancialidade das relações sociais, não apenas para produzir conhecimento, mas para subsidiar a emancipação de mulheres e homens de todas as etnias frente ao capitalismo, ao racismo e ao patriarcado. Este parece ser o caminho para libertar-se da pauperização das classes trabalhadoras, inerente ao capitalismo, do racismo e do machismo, que também se reproduzem nas estruturas de bem-estar social da África do Sul pós-Apartheid. 


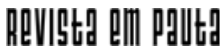

\} PIGMENTOCRACIA: CLASSE, RAÇA E GÊNERO - BARBOSA FILHO, E. A.; VIEIRA, A. C. S.; ROCHA, S. \}

DOI: $10.12957 /$ REP.2019.45247

\section{Referências}

AFRICAN NATIONAL CONGRESS. The freedom charter. Johannesburg: Pacific Press, 1955.

ARENDT, $\mathrm{H}$. As origens do totalitarismo: antissemitismo, imperialismo, totalitarismo. São Paulo: Companhia das Letras, 2012.

DAVIE, G. Poverty knowledge in South Africa: a social history of human science, 1855-2005. New York: Cambridge University Press, 2015.

FEINSTEIN, C. An economic history of South Africa: conquest, discrimination and development. Cambridge: Cambridge University Press, 2005.

KLAUSEN, S. Race, maternity, and the politics of birth control on South Africa. United Kingdom: Palgrave MacMillan, 2004.

PATEL, L. Social welfare \& social development in South Africa. Cape Town: Oxford University Press, 2013.

SEEKINGS, J.; MOORE, E. Kin, market and State in the provision of care in South Africa. Cape Town: Centre for Social Science Research University of Cape Town, 2013.

TERREBLANCHE, S. A history of inequality in South Africa 1652-2002. Pietermaritzburg: University of Natal Press, 2005.

TERREBLANCHE, S. Lost in transformation: South Africa's search for a new future since 1986. Johannesburg: KMM, 2012.

CARNEGIE COMISSION. The poor white problem in South Africa. Report of the Carnegie Commission, Joint Findings and Recommendations, 1932.

SOUTH AFRICA. The Parliament of South Africa. Debates of the house of assembly. Pretoria: Union of South Africa, 8 maio 1934.SOUTH AFRICA. The Republic of South Africa. Growth, employment and redistribution (Gear). Pretoria: State Printers, 1996.

DOI: $10.12957 /$ rep.2019.45247

Recebido em 03 de julho de 2018.

Aprovado para publicação em 22 de setembro de 2018.

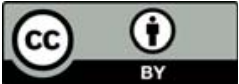

A Revista Em Pauta: Teoria Social e Realidade Contemporânea está licenciada com uma Licença Creative Commons Atribuição 4.0 Internacional. 